\title{
PENERAPAN DATA MINING UNTUK PREDIKSI PENJUALAN WALLPAPER MENGGUNAKAN ALGORITMA C4.5
}

\author{
Juna Eska \\ STMIK Royal, Ksiaran \\ Email: dosen.junaeska@gmail.com
}

\begin{abstract}
Abstrak
Wallpaper dinding rumah atau kertas dinding merupakan hiasan dinding dengan bermacam motif dan warna. Kertas dinding digunakan untuk mengubah penampilan suatu ruang agar semakin cantik dan memiliki nilai tambah. Dinding rumah yang polos cenderung membuat penghuni rumah merasa bosan karena tampilan dinding yang monoton. Untuk itu, memiliki inisiatif mendesain dinding rumah dengan wallpaper menjadi satu ide cemerlang yang harus dicoba. Mewarnai dinding rumah dengan wallpaper memang bisa menambah kesan indah pada suatu ruangan, sehingga ruangan terlihat lebih ekspresif. Bermacam motif, warna, dan corak wallpaper dapat dipilih. Oleh karena itu penjual harus lebih cermat menyediakan wallpaper mana yang akan banyak peminatnya, sehingga perlu perekomendasian jenis jenis wallpaper dengan menggunakan metode Klasifikasi dilakukan menggunakan data mining algoritma C4.5. data yang diperlukan yaitu data merk wallpaper terbaik, warna, motif, kualitas bahan, ukuran, dan harga. Algoritma C4.5 adalah algoritma klasifikasi data bertipe pohon keputusan. Pohon keputusan Algoritma C4.5 dibangun dengan beberapa tahap yang meliputi pemilihan atribut sebagai akar, membuat cabang untuk tiap-tiap nilai dan membagi kasus dalam cabang. Tahapan-tahapan ini akan diulangi untuk setiap cabang sampai semua kasus pada cabang memiliki kelas yang sama. Dari penyelesaian pohon keputusan maka akan didapatkan beberapa rule.
\end{abstract}

Kata kunci : Data Mining, Wallpaper, Algoritma C4.5

\begin{abstract}
Wallpaper wallpaper or wallpaper wall is a wall decoration with a variety of motifs and colors. Wallpaper is used to change the appearance of a space to be more beautiful and has added value. Plain house walls tend to make the occupants of the house feel bored because of the monotonous wall appearance. For that, having the initiative to design the wall of the house with wallpaper into a bright idea that should be tried. Coloring the walls of the house with wallpaper can add a beautiful impression on a room, so the room looks more expressive. Various motifs, colors, and wallpaper styles can be selected. Therefore, the seller must be more careful to provide wallpaper which will be a lot of devotees, so it is necessary to recommend the type of wallpaper type using Classification method is done using data mining algorithm C4.5. data required is the best wallpaper brand data, color, motif, material quality, size, and price. Algorithm C4.5 is a data classification algorithm of type of decision tree. The decision tree The C4.5 algorithm is constructed with several stages including the selection of attributes as roots, creating branches for each value and dividing instances in branches. These stages will be repeated for each branch until all the cases on the branch have the same class. From the completion of the decision tree there will be some rules.
\end{abstract}

Keywords: Data Mining, Wallpaper, Classification, Algorithm C4.5

\section{PENDAHULUAN}

\subsection{Latar Belakang Masalah}

Saat ini, untuk memperindah dinding tidak selalu menggunakan cat dinding, namun ada berbagai alternatif telah tersedia. Dalam suatu rumah, dinding merupakan bagian yang paling dominan yang selalu mengelilingi kita. Sehingga, bagian ini pula yang paling sering kita lihat saat berada di rumah. Dinding dalam bangunan rumah tidak hanya dipandang sebagaipemisah antar ruang, tetapi juga menjadi media bagi penghuni untuk mengekspresikan diri.

Salah satu alternatif, untuk penutup dinding yang digemari saat ini adalah wallpaper atau kertas dinding. 
Dalam kehidupan sehari-hari, dengan sadar maupun tidak sadar manusia saat ini sudah terpengaruh oleh berbagai produk dan desain yang ada disekitarnya, misalnya saja desain wallpaper yang dapat membuat seseorang merasa betah didalam suatu ruangan. Banyak faktor yang dapat menjadi pengaruh jika berbicara mengenai pemilihan sebuah desain wallpaper untuk dinding rumah, konsumen dihadapkan pada berbagai macam pilihan merk dengan variasi warna dan desain yang berbeda-beda. Selain itu untuk menghitung biaya yang dibutuhkan, diperlukan perhitungan yang cukup rumit. Hal tersebut mengakibatkan konsumen seringkali mengalami kesulitan dalam memilih wallpaper.

Perkembangan teknologi komputer yang selalu berkembang dalam usaha memenuhi kebutuhan manusia di bidang komunikasi, informasi dan pengolahan data. Sebagai contoh penjualan wallpaper yang berkembang dan tumbuh sangat cepat. Dengan semakin meningkatnya konsumen yang membutuhkan wallpaper, maka semakin banyak pula permasalahan yang timbul di dalam memberikan pelayanannya kepada pelanggan. Sistem persediaan wallpaper harus disiapkan dengan maksimal agar penjual dapat memenuhi keinginan konsumen.

Untuk mempermudah penjual memilih wallpaper mana yang banyak diminati konsumen agar disediakan stok untuk wallpaper tersebut, maka perlu diprediksi untuk penjualan wallpaper terbanyak dengan metode klasifikasi menggunakan metode data mining algoritma c4.5.

\subsection{Rumusan Masalah}

Berdasarkan pada latar belakang masalah, maka dapat ditemukan masalah yang akan diselesaikan yaitu merancang suatu sistem yang dapat membantu penjual dalam mengambil keputusan untuk memprediksi produk merk wallpaper mana yang banyak diminati konsumen.

\subsection{Batasan Masalah}

Adapun batasan-batasan masalah dalam penelitian ini adalah :

1. Penelitian ini hanya sebagai alat bantu bagi pihak penjual dalam menentukan produk mana yang banyak diminati oleh konsumen.

2. Metode yang digunakan dalam perancangan sistem ini adalah Algorima C4.5.

3. Output dari penelitian ini adalah urutan prioritas merk wallpaper yang cocok untuk distok agar laku di pasaran.

\section{LANDASAN TEORI}

\subsection{Data Mining}

Data mining adalah proses yang mempekerjakan satu atau lebih teknik pembelajaran computer (machine learning) untuk menganalisis dan mengekstrasi pengetahuan (knowledge) secara otomatis. Definisi lain diantaranya adalah pembelajaran berbasis induksi (induction-basedlearning) adalah proses pembentukan definisi-definisi konsep umum yang dilakukan dengan cara mengobservasi contoh-contoh spesifik dari konsepkonsep yang akan dipelajari. Knowledge Discovery in Databases (KDD) adalah penerapan metode saintifik pada data mining. Dalam konteks ini data mining merupakan satu langkah dari proses KDD [1].

Beberapa teknik dan sifat data mining adalah sebagai berikut:

a. Classification [Predictive]

b. Clustering [Descriptive]

c. AssociationRule Discovery [Descriptive]

d. Regression [Predictive]

e. DeviationDetection [Predictive]

Karena data mining adalah sebuah untain proses, maka pecah menjadi beberapa tahap. Tahapan tersebut akan bersifat interaktif, pengguna akan terlibat langsung atau dengan perantara $\mathrm{KDD}[2]$.

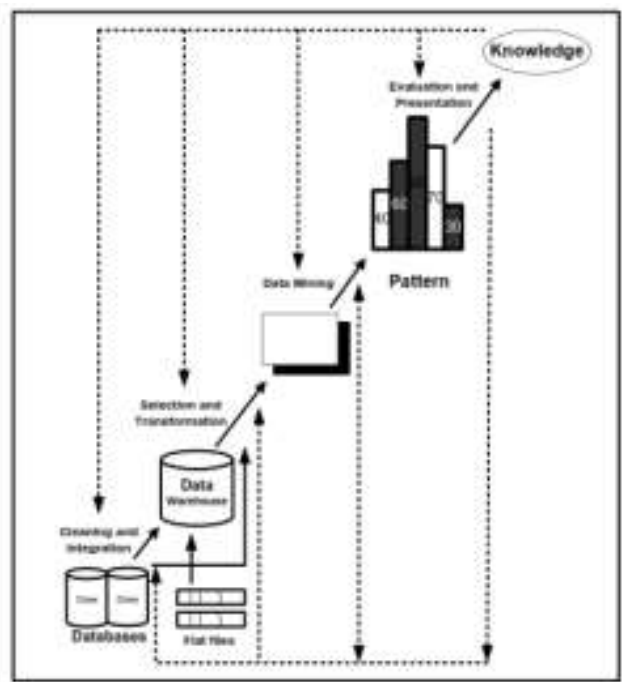

Tahapan data mining dibagi menjadi enam bagian yaitu :

1. Pembersihan data (data cleaning)

Sebelum proses data mining dapat dilaksanakan, perlu dilakukan proses cleaning pada data yang menjadi fokus KDD. Proses cleaning mencakup antara lain membuang 4 duplikasi data, 
memeriksa data yang inkonsisten, dan memperbaiki kesalahan pada data, seperti kesalahan cetak (tipografi). Juga dilakukan proses enrichment, yaitu proses "memperkaya" data yang sudah ada dengan data atau informasi lain yang relevan dan diperlukan untuk KDD, seperti data atau informasi eksternal.

2. Integrasi data (data integration)

Integrasi data merupakan penggabungan data dari berbagai database ke dalamsatu database baru. Tidak jarang data yang diperlukan untuk data mining tidak hanya berasal dari satu database tetapi juga berasal dari beberapa database ataufile teks. Integrasi data dilakukan pada atribut-aribut yang mengidentifikasikanentitas-entitas yang unik seperti atribut nama, jenis produk, nomor pelanggandan lainnya. Integrasi data perlu dilakukan secara cermat karena kesalahan padaintegrasi data bisa menghasilkan hasil yang menyimpang dan bahkanmenyesatkan pengambilan aksi nantinya. Sebagai contoh bila integrasi databerdasarkan jenis produk ternyata menggabungkan produk dari kategori yangberbeda maka akan didapatkan korelasi antar produk yang sebenarnya tidak ada.

3. Seleksi Data (Data Selection)

Data yang ada pada database sering kali tidak semuanya dipakai, oleh karena ituhanya data yang sesuai untuk dianalisis yang akan diambil dari database. Sebagai contoh, sebuah kasus yang meneliti faktor kecenderungan orangmembeli dalam kasus market basket analysis, tidak perlu mengambil namapelanggan, cukup dengan id pelanggan saja.

4. Transformasi data (Data Transformation)

Data diubah atau digabung ke dalam format yang sesuai untuk diproses dalamdata mining. Beberapa metode data mining membutuhkan format data yangkhusus sebelum bisa diaplikasikan. Sebagai contoh beberapa metode standarseperti analisis asosiasi dan clustering hanya bisa menerima input datakategorikal. Karenanya data berupa angka numerik yang berlanjut perlu dibagibagimenjadi beberapa interval. Proses Ini seringdisebut transformasi data.

5. Proses mining.

adalah sebuah proses yang paling utama pada saat metode diterapkan untuk mencari pengetahuan tersembunyi dan berharga dari data.

6. Evaluasi pola (pattern evaluation), Untuk mengidentifikasi pola-pola menarik kedalam knowledge based yang ditemukan.
Dalam tahap ini hasil dari teknik data mining berupa pola-pola yang khas maupun model prediksi dievaluasi untuk menilai apakah hipotesa yang ada memang tercapai.

7. Presentasi pengetahuan (knowledge presentation),

Merupakan penyajian dan visualisasi pengetahuan mengenai metode yang digunakan untuk memperoleh pengetahuan yang diperoleh pengguna. Tahap terakhir dari proses data mining adalah bagaimana memformulasikan keputusan atau 5 aksi dari hasil analisis yang didapat. Ada kalanya hal ini harus melibatkan orangorang yang tidak memahami data mining. Karenanya presentasi hasil data mining dalam bentuk pengetahuan yang bisa dipahami semua orang adalah satu tahapan yang diperlukan dalam proses data mining. Dalam presentasi ini,visualisasi juga bisa membantu mengkomunikasikan hasil data mining [3].

\subsection{Algoritma C4.5}

Algoritma C4.5 merupakan algortima yang digunakan untuk membentuk pohon keputusan. Pohon keputusan merupakan metodeklasifikasi dan prediksi yang sangat kuat dan terkenal. Metode pohon keputusa mengubah fakta yang sangat besar menjadi pohon keputusanyang merepresentasikan aturan. Aturan dapat dengan mudah dipahamidengan bahasa alami. Dan mereka juga dapat diekspresikan dalam bentukbahasa basis data seperti Structured Query Language untuk mencari record pada kategori tertentu [4].

Cara algoritma C4.5 untuk membangun pohon keputusan yaitu:

a. Pilih atribut yang akan digunakan sebagai akar

b. Buatlah sebuah cabang untuk setiap nilai

c. Bagilah kasus dalam sebuah cabang

d. Ulangi proses untuk setiap cabang sampai semua kasus pada cabang memiliki kelas yang sama.

Ada beberapa tahap dalam membuat sebuah pohon keputusan dengan algoritma C4.5 [5].

1. Menyiapkan data training. Data ini diambil dari data yang sudah pernah ada sebelumnya dan sudah dikelompokan kedalam kelas tertentu.

2. Setalah itu tentukan akar dari pohon. Pilih akar dari atribut, cara adalah dengan menghitung nilai gain dari semua atribut, yang menjadi akar pertama adalah nilai gain yang paling. Sebelum menentukan nilai gain, terlebih dahulu hitung nilai entropy. 
Untuk menentukan nilai entropy gunakan rumus :

\author{
Entropy $(S)=\sum_{i=1}^{n}-\mathbf{p i} \cdot \log 2 \mathbf{p i}$ \\ Keterangan : \\ $\mathrm{S}=$ himpunan kasus \\ $\mathrm{n}=$ jumlah partisi $\mathrm{S}$ \\ pi $=$ proporsi $S_{i}$ terhadap $S$
}

3. Setelah itu tentukan nilai gain menggunakan rumus:

$\operatorname{Gain}(S, A)=\operatorname{Entropy}(S)-\sum_{i=1}^{n} \frac{|S i|}{|S|} * \operatorname{Entropy}(S i)$

Keterangan :

$\mathrm{S}=$ Himpunan Kasus

$\mathrm{A}=$ Atribut

$\mathrm{n}=$ Jumlah Partisi Atribut A

$|\mathrm{Si}|=$ Jumlah Kasus pada partisi ke-i

$|\mathrm{S}|=$ Jumlah Kasus dalam $\mathrm{S}$

4. Setelah itu ulangilah langkah ke-2 sampai semua record terpartisi secara sempurna.

5. Proses partisi pohon keputusan akan berhenti saat :

a. Semua record dalam simpul $\mathrm{N}$ mendapat kelas yang sama.

b. Tidak ada atribut di dalam record yang dipartisi lagi.

c. Tidak ada record di dalam cabang yang kosong.

\subsection{Decision Tree}

Pohon (tree) adalah sebuah struktur data yang terdiri dari simpul (node) dan rusuk (edge). Simpul pada sebuah pohon dibedakan menjadi tiga, yaitu simpul akar (root node), simpul percabangan/ internal (branch/ internal node) dan simpul daun (leaf node), [6].

Pohon keputusan merupakan representasi sederhana dari teknik klasifikasi untuk sejumlah kelas berhingga, dimana simpul internal maupun simpul akar ditandai dengan nama atribut, rusuk-rusuknya diberi label nilai atribut yang mungkin dan simpul daun ditandai dengan kelas-kelas yang berbeda [6].

\section{PEMBAHASAN}

\subsection{Perhitungan Manual}

Tabel.1 Data Wallpaper

\begin{tabular}{|c|c|c|c|c|c|c|}
\hline $\mathrm{No}$ & Frga & Daxan & Frniah Metif & Kaífas Babae & Tiama & 3Ena: \\
\hline 1 & Jahat & Bear & Sé́liti & Bez & Baryzik & Sestit: \\
\hline 2 & Jahat & Kacil & Baryzk & Terbal: & Baryzk & Beryá \\
\hline 3 & Mrah & Keal & Baryak & Bèk & Baryzk & Baryak \\
\hline 4 & Jakat & Bear & Seskit & Terba: & Baryzk & Sent: \\
\hline 5 & Mrah & Bear & Seślit & Tertal: & Eeślat & Seâkit: \\
\hline 6 & Mrah & Bear & Sef́lit & Tetoz: & Baryz & Seats: \\
\hline 7 & Mrah & Bear & Eeślit & Tental: & Baryz & Sexis: \\
\hline 8 & Mrah & Kacil & Baryat & Terta?: & Baryzk & Beryat: \\
\hline 9 & Jahal & Bear & Baryak & Terbz: & Baryzk & Baryak \\
\hline 10 & Jaka1 & Kacil & Baryak & Tetaz: & Baryzk & Barya \\
\hline 11 & Mrah & Bear & Baryak & Bezk & Baryzk & Baryak \\
\hline 12 & Jahal & Bear & Seǵsit & $\mathrm{Bez}$ & Enskit & Sestit: \\
\hline 13 & Nahat & Kaeil & Baryak & Tetra? & Seschit & Sestit: \\
\hline 14 & Jakal & Kael & Seǵbit & Tetal: & Seskit & Seatit: \\
\hline 15 & Jahat & Keal & Baryak & Tetbz: & Seskit & Seati: \\
\hline 16 & Jakal & Kael & Baryak & Bezk & Seślit & Seatst: \\
\hline 17 & Jakal & Bear & Seckit & Bazk & Seskit & Seabs: \\
\hline 18 & Mrah & Keal & SeÉbit & Bez: & Seskit & Sent: \\
\hline 19 & Mrah & Kael & Baryzk & Bab & Seskit & Baryat \\
\hline 20 & Jahal & Bear & Baryzk & Tental: & Baryzk & Beryak \\
\hline 21 & Jahal & Bear & Segbit & Betz & Baryzk & Senti: \\
\hline 22 & Jabal & Kael & Seskit & Bez & Baryzk & Se6kit: \\
\hline 23 & Jakal & Bear & Seásit & Bez: & Baryzk & Seakst: \\
\hline 24 & Nahat & Kael & Baryak & Bezk & Baryzk & Beryak \\
\hline 25 & Jahat & Bear & Baryzk & Bez & Baryzk & Baryat: \\
\hline 26 & Jahal & Keal & Baryzk & Bet: & Baryzk & Sexki: \\
\hline 27 & Mrah & Kaeil & Baryak & Tentz: & Baryzk & Señit: \\
\hline 28 & Marah & Bear & Baryzk & Terba?: & Baryzk & Bergat: \\
\hline 29 & Marah & Real & Baryzk & Bek & Baryzk & Seastit: \\
\hline 30 & Mrah & Bear & Bascak & Tentz: & Baryzk & Bargak \\
\hline
\end{tabular}

Pada tabel di atas terdapat 30 penilaian dari 6 penilaian yang menentukan minat konsumen terhadap wallpaper

Tabel.2 Nilai Gain dan Nilai Entropy

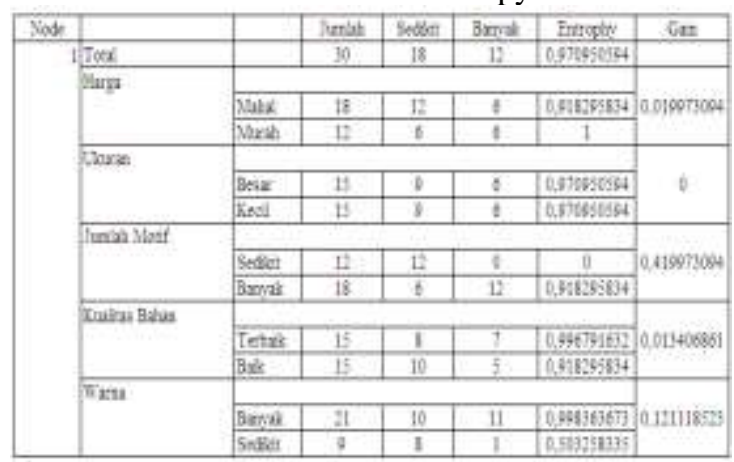

Tabel di atas dapat diketahui bahwa Gain tertinggi adalah jumlah motif yaitu sebesar 0.419973 . Dengan demikian, jumlah motif dapat menjadi node akar. Ada dua nilai atribut dari jumlah motif, yaitu banyak dan sedikit, sehingga perlu dilakukan perhitungan lagi. 


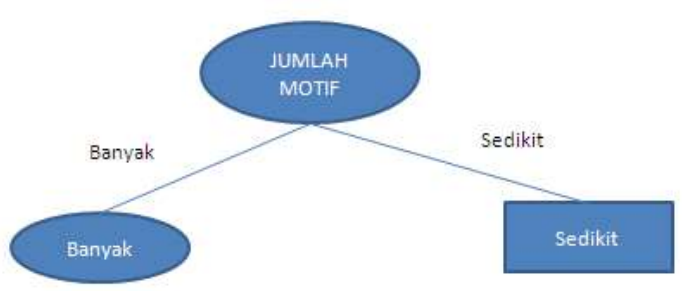

Gambar 1 Decision Tree

Pada gambar di atas dapat diambil keputusan bahwa jika jumlah motif banyak maka minat konsumen banyak. Jika jumlah motif sedikit maka minat konsumen sedikit.

\subsection{Rapid Miner}

Setelah dilakukan dengan perhitungan menggunakan excel, selanjutnya dilakukan perhitungan menggunakan aplikasi rapid miner. Setelah diproses, maka di dapatkan decision tree dibawah ini.

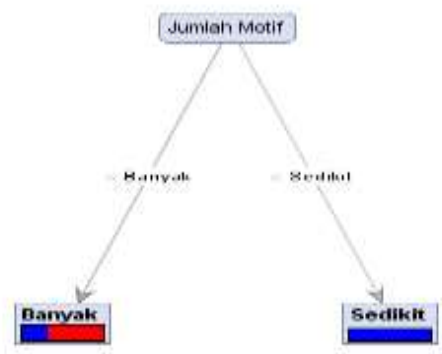

Gambar 2 Decision Tree dengan Rapid Miner

\section{DAFTAR PUSTAKA}

1. Turban, Efraim \& Aronson, Jay E. 2001. Decision Support Systems and Intelligent Systems. 6th edition. Prentice Hall: Upper Saddle River, NJ

2. L. A. Abdillah, "Students learning center strategy based on e-learning and blogs," in Seminar Nasional Sains dan Teknologi (SNST) ke-4 Tahun 2013, Fakultas Teknik Universitas Wahid Hasyim Semarang 2013, pp. F.3.15-20.

3. V Wiratna Sujarweni, Metodologi Penelitian. Yogyakarta: PUSTAKABARUPERSS, 2014.

\section{Tree}

Jumlah Motif = Banyak: Banyak $\{$ Sedikit $=6$, Banyak $=12\}$

Jumlah Motif $=$ Sedikit: Sedikit $\{$ Sedikit $=12$, Banyak $=0$ \}

\section{KESIMPULAN DAN SARAN}

4.1 Kesimpulan

Berdasarkan hasil penelitian yang dilakukan, maka penulis dapat menarik kesimpulan bahwa pembelian wallpaper dengan menggunakan metode Data Mining khususnya Algoritma C4.5 akan bermanfaat sekali dalam proses pengambilan keputusan dalam pembelian wallpaper.

1. Yang menjadi faktor tertinggi yang mempengaruhi penjualan adalah faktor jumlah motif wallpaper.

2. Faktor Harga, Ukuran, Kualitas Bahan, dan Warna tidak mempengaruhi pembelian karena wallpaper dengan harga mahal, ukuran yang kecil, kualitas bahan yang baik, dan warna yang sedikit ternyata masih diminati oleh pelanggan.

\subsection{Saran}

Adapun saran-saran yang disampaikan berdasarkan hasil pengamatan dan analisa selama melakukan penelitian adalah:

1. Penelitian selanjutnya sebaiknya menggunakan data yang lebih banyak agar menghasilkan rules yang lebih akurat.

2. Penelitian selanjutnya sebaiknya menggunakan atribut yang lebih banyak agar menghasilkan data yang lebih akurat.

4. Kusrini and Emha Taufiq Luthfi, Algoritma Data Mining. Yogyakarta: ANDI, 2009.

5. Rahmadya T. H dan Herlawati Prabowo P. W, Penerapan Data Mining dengan Matlab. Bandung: Rekayasa Sains, 2013.

6. Hermawati. F. Astuti. (2013). Data Mining. Yogyakarta: Andi Offset. 
JURTEKSI (Jurnal Teknologi dan Sistem Informasi)

Vol 2, Nomor 2, Maret 2016, hlmn 9- 13

ISSN 2407 - 1811 